\title{
Postprandial Lipid Metabolism: The Missing Link Between Life-Style Habits and the Increasing Incidence of Metabolic Diseases in Western Countries?
}

\author{
Elena Bravo ${ }^{*, 1}$, Mariarosaria Napolitano ${ }^{1}$ and Kathleen M. Botham ${ }^{2}$ \\ ${ }^{I}$ Department of Cellular Biology and Neuroscience, Istituto Superiore di Sanità, Rome, Italy \\ ${ }^{2}$ Department of Veterinary Basic Sciences, The Royal Veterinary College, London, UK
}

\begin{abstract}
Postprandial lipemia is the transient increase in blood lipids which occurs after a meal containing fat and is caused by raised levels of triglyceride-rich lipoproteins (TRLs) in the blood. Delayed clearance of TRLs leads to postprandial hyperlipidemia, and there is now a great deal of evidence to support the idea that this condition is an important risk factor for cardiovascular disease (CVD). Western lifestyle habits including: diets low in fresh fruit and vegetables and high in fat and processed food, alcohol consumption, smoking, and lack of exercise tend to promote postprandial hyperlipidemia, and it is a characteristic feature of increasingly common metabolic diseases such as obesity, insulin resistance and type 2 diabetes which are also linked to modern lifestyle behaviour and which carry an increased risk of CVD development. Modification of lifestyle factors such as changing to a healthier diet, weight loss, reducing alcohol consumption and increasing exercise can cause significant reductions in postprandial hyperlipidemia and thus help to reduce this risk. Despite the growing recognition that the extent of postprandial lipemia is a good predictor of CVD, no standardized methodology for its measurement is currently available. Determination of blood TG levels after consumption of a standard test meal is likely to be the most convenient approach for a routine clinical test, and we propose a standard test meal which is easily adaptable for the variations in dietary habits in different countries. Greater use of postprandial lipid determination will aid in the translation of our extensive knowledge on the role of nutrition in health into national and international policy.
\end{abstract}

Keywords: Lifestyle, type 2 diabetes, obesity, postprandial lipemia, triglyceride-rich lipoproteins.

\section{INTRODUCTION}

Cardiovascular disease (CVD) is the main cause of death in Western countries, accounting for over $42 \%$ of the total each year in the European Union (EU) [1] and for $34.2 \%$ in the United States (data for 2006) [2]. The main forms of CVD are coronary heart disease (CHD) and stroke. CHD is the single most common cause of death in Western countries. Data for the EU, shown in Table 1, indicate that approximately one in six $(16 \%)$ men and more than one in seven $(15 \%)$ women die from this disease, while stroke, the second most common cause of death, kills about $9 \%$ of men and $12 \%$ of women. In the United States (data for 2005), CHD caused about 1 in every 5 deaths and stroke about 1 in every 7.5 deaths [2].

The burden of CVD (illness and death) can be measured using the disability adjusted life year (DALY), which is an aggregate of the years of life lost due to premature death and years of healthy life lost because of disability. In the EU, $19 \%$ of the total DALYs are lost because of CVD (Table 1). Moreover, in addition to the human costs there are major economic costs, estimated to be $€ 192$ billion per year. The cost of heart disease and stroke in the United States, includ-

*Address correspondence to this author at the Department of Cellular Biology and Neuroscience, Istituto Superiore di Sanità, Viale Regina Elena 299 00161 Rome, Italy; Tel: +3906 49903061 // 2730 / 2867; Fax: +3906 4938 7143; E-mail: bravo@iss.it ing health care expenditure and lost productivity from deaths and disability, is projected to be more than $\$ 475$ billion in 2009 [2]. About $10 \%$ of the total EU health expenditure is due to CVD, of which $57 \%$ is accounted for by direct health care, $21 \%$ by productivity losses due to mortality and morbidity and $22 \%$ by the informal care of individuals with CVD. CHD and stroke are each responsible for about one fifth of the costs of CVD, although stroke causes less productivity loss due to mortality, but has a higher cost for informal care (Table 1).

Despite the grim statistics outlined above, it is increasingly clear that the risk of CVD can be significantly reduced by relatively easily achievable lifestyle changes, such as switching to a healthier diet, higher in fruit, vegetable and fiber and lower in fat and digestible carbohydrate, increasing exercise and stopping smoking [3]. Postprandial lipemia is now recognised as a risk factor for atherosclerosis, a major cause of CVD (see below), and strong evidence indicates that it is influenced not only by the amount and type of fat consumed, but also by other lifestyle factors such dietary intake of protein, fibre and micronutrients as well as by exercise, alcohol consumption and smoking [4,5]. Since postprandial hyperlipidemia is a feature of increasingly common diseases associated with the Western lifestyle which increase CVD risk, including obesity, insulin resistance and diabetes [4], the condition may represent a link between current lifestyle habits and the rapidly rising incidence of these diseases. This article reviews current knowledge concerning the influ- 
Table 1. Burden of Cardiovascular Disease in the EU

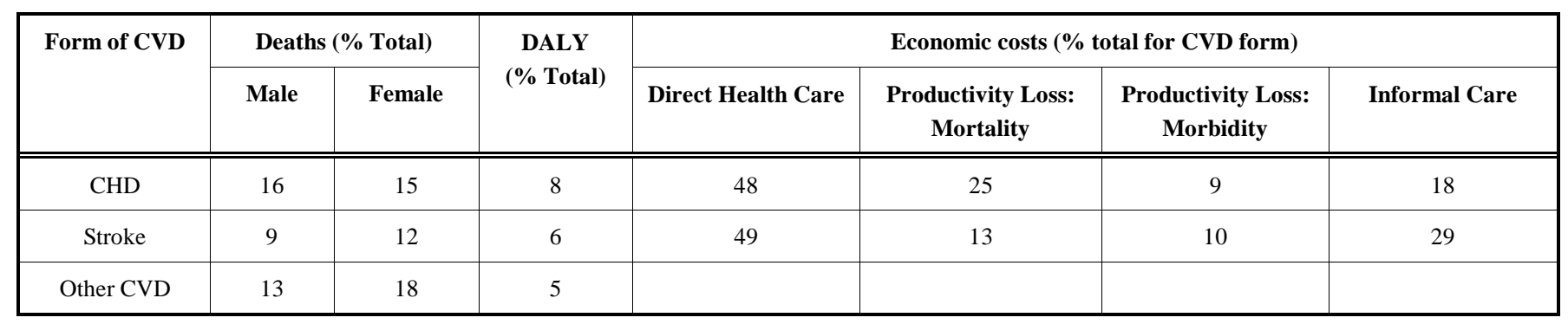

Data from European cardiovascular disease statistics 2008 [Allender S, Scarborough P, Peto V, Rayner M, Leal J, Luengo Fernandez R, Gray A. (2008) European Heart Network www.ehnheart.org. DALY; disability adjusted life year.

ence of lifestyle choices on postprandial lipemia and the potential benefits of its routine clinical measurement, and suggests some guidelines for a widely applicable routine test.

\section{POSTPRANDIAL HYPERLIPIDEMIA AS A RISK FACTOR FOR ATHEROSCLEROSIS}

Postprandial lipemia refers to the transient increase in blood lipids, particularly triacylglycerols (TG) which occurs after a meal containing fat [5]. It has been estimated, however, that individuals consuming a typical Western spend approximately 18 hours per day in this state [6]. Lipids from the diet, including macronutrients such as fats and micronutrients such as lipid soluble antioxidants, are absorbed in the intestine and packaged into chylomicrons (CM) inside intestinal cells. These large, TG-rich lipoproteins are then secreted into lymph and pass into the blood via the thoracic duct. Here, they are rapidly lipolyzed by lipoprotein lipase (LPL) in extrahepatic capillary beds, forming smaller, but still TG-rich, chylomicron remnants (CMR) which deliver the remaining TG and the other dietary lipids to the liver $[7,8]$. Once inside the liver, the fatty acids derived from the TG may be used to obtain energy or for the synthesis of complex lipids such as phospholipids. Alternatively, however, they may be re-synthesized into TG, packaged together with cholesterol and phospholipid into very low density lipoprotein (VLDL) and returned to the blood [9]. Since hepatic VLDL secretion is increased postprandially [10], postprandial lipemia is caused by raised levels of CM, CMR and VLDL in the blood. These lipoprotein classes cannot be easily separated from blood samples taken postprandially and are collectively referred to as triglyceride-rich lipoproteins (TRLs).

Thirty years ago, it was first proposed by Zilversmit [11] that postprandial lipemia may play a role in atherogenesis, and there is now a great deal of evidence from epidemiological, clinical and experimental studies to support the idea that postprandial hyperlipidemia is an important risk factor for atherosclerosis and the progression of cardiovascular disease [12-15]. Nakajima and colleagues have reported that the majority of sudden cardiac deaths in a Japanese cohort of patients were associated with postprandial hyperlipidemia [16] and that plasma remnant lipoprotein levels were the major pathological factor involved [17]. Postprandial hyperlipidemia or raised plasma remnant lipoprotein levels have also been linked with increased carotid artery intima thickness in humans $[18,19]$ and in a rabbit model of hereditary postprandial hypertriglyceridemia [20]. Furthermore, delayed clearance of TRLs has been linked with atherosclerosis pro- gression in a number of studies [12, 21-23] and in two recent large scale prospective trials, non fasting plasma TG levels were found to be related to the incidence of cardiovascular events independently of other risk factors [24, 25].

Current evidence suggests that postprandial lipoproteins may be involved in promoting atherosclerosis both directly, via an influence on events in the vasculature, and indirectly, by causing a more atherogenic lipoprotein profile when their levels are abnormally raised [12, 14, 26]. Atherosclerosis is initiated by dysfunction of the vascular endothelium followed by the formation of macrophage foam cells, generated by the scavenging of lipids from plasma lipoproteins. Accumulation of foam cells and the proliferation of vascular smooth muscle cells (VSMCs) then causes the appearance of fatty streaks, the first visible lesions in the vessel wall [27]. CMR have been shown to penetrate the artery wall and to be retained within the intima [28-30], and remnant-like lipoproteins have been found in human atherosclerotic plaque [3133]. CMR and TRLs have also been demonstrated to cause endothelial dysfunction [34-38], macrophage foam cell formation [34, 39] and the proliferation of VSMCs [34]. Other pro-inflammatory and potentially atherogenic effects of postprandial lipoproteins include activation of leukocytes, promoting adhesion to the endothelium and invasion of the artery wall $[12,40]$. In addition, postprandial lipemia causes pro-thrombotic effects such as increasing coagulant factor VII [41] and plasminogen activator inhibitor type 1(PAI-1) activity [42] and increasing platelet activity $[14,43]$ and aggregation [44].

Small dense low density lipoprotein (LDL) are thought to be more atherogenic that larger LDL particles because they enter the vessel wall more easily, are more prone to oxidative modification, bind more tightly to the arterial wall and are cleared more slowly [45, 46]. The composition of TRLs is metabolically linked to that of LDL, with plasma TG levels being the main factor influencing LDL particle size [47], and it has been demonstrated that postprandial hyperlipidemia is associated with an increase in the proportion of small, dense LDL [46, 48-50]. In addition, prolonged lipemia leads to increased opportunity for the transfer of core lipids between TRLs and high density lipoprotein (HDL), leading to a reduction in HDL cholesterol levels [14]. This combination of high plasma TG concentrations, increased small dense LDL and low HDL is known as the lipid triad or atherogenic lipoprotein profile [51].

Postprandial lipemia is modulated by many lifestyle factors, including diet, exercise, drinking and smoking, and post- 
prandial hyperlipidemia is a feature of diseases linked to the Western lifestyle, including obesity, insulin resistance and diabetes [4]. Improvements in lifestyle, therefore, should be the first target to control postprandial hyperlipidemia and to reduce the associated risk of cardiovascular disease.

\section{LIFESTYLE AND POSTPRANDIAL LIPEMIA}

Although postprandial lipemia is a transient effect which occurs after a fat-containing meal, Western dietary habits of consuming three meals day, often with snacking in between, means that plasma TG levels remain elevated and continually fluctuate in a dynamic, non steady state throughout the day $[4,5]$. Clearly, the changes in lipemia will be highly variable from individual to individual depending on the frequency of food intake and the fat (amount and type) composition of the meals. Perhaps less obviously, however, there are a number other modifiable diet and lifestyle factors which play a modulatory role, including the carbohydrate (digestible and fibre), protein and micronutrient content of the food, long term dietary habits, alcohol intake, smoking and the amount of exercise taken, as well as non modifiable factors such as age, gender and genetics [4, 5, 52]. Lifestyle factors affecting postprandial lipemia are summarised in Fig. (1).

\section{Diet}

Fat meals containing > 30g fat have been shown to cause postprandial lipemia, with dose dependence up to about $80 \mathrm{~g}$ $[4,52,53]$. Comparing this to the average content of $20-40 \mathrm{~g}$ fat in Western style meals and a typical dietary habit of 3-4 meals/day leads to the conclusion that postprandial triglyceridemia commonly lasts for $18 \mathrm{~h} /$ day in the population of developed countries [6].

Acute studies testing the effects of single meals supplemented with different types of fats have shown that n-3 polyunsaturated fatty acids (PUFA) from fish oil attenuate the postprandial rise in blood TG levels $[4,52,54]$ compared to other types of fat, and the saturated fatty acid (SFA) stearic acid found in animal fat has also been reported to have this effect [55-57]. In addition, changes in TRL particle size and number and lipid and apolipoprotein (apo) composition depending on the type of fat in the meal have been demonstrated, with SFA causing the most pronounced lipemia by these criteria, followed by monounsaturated fatty acids (MUFA) (high in olive oil) and then PUFA [4]. It is clearly important, however, to assess the effects of the consumption of different types of fat in the longer term (ie over a period of weeks or months) on postprandial lipemia, since sustained changes in dietary habits are likely to be necessary for beneficial effects on health. The effects of dietary supplementation with n-3 PUFAs in reducing fasting plasma TG levels are well established (see [58] for a recent review), and a number of studies have shown that they also reduce postprandial hypertriglyceridemia, both when chronically present in the diet and when given as a supplement for periods from 4 weeks to 6 months, in normal and hyperlipidemic subjects and in male smokers [59-63]. Moreover, the TG lowering effect has been attributed to a decrease in chylomicron and VLDL production $[59,61]$. Other types of fatty acids tend to have less marked effects on postprandial lipemia than n-3 PUFA, but, in general, diets containing or supplemented with MUFA and n-6 PUFA as compared to SFA (found in plant oils) have been found to cause a reduced response [4, 52].

The carbohydrate content of the diet is also believed to influence postprandial lipemia (for a review see [64]). Although there is no consistent evidence to suggest that glucose has any effect, dietary fructose, when given both as the monosaccharide and in the disaccharide, sucrose (sugar), has been shown to enhance the response in a number of studies [4, 64]. A recent meta-analysis covering studies published between 1966 and 2006, however, concluded that there was no significant effect on postprandial blood triacylglycerol levels at doses below 50g/day [65]. Foods high in starch which are common in the Western diet, such as white bread and pasta, do not appear to increase postprandial lipemia,

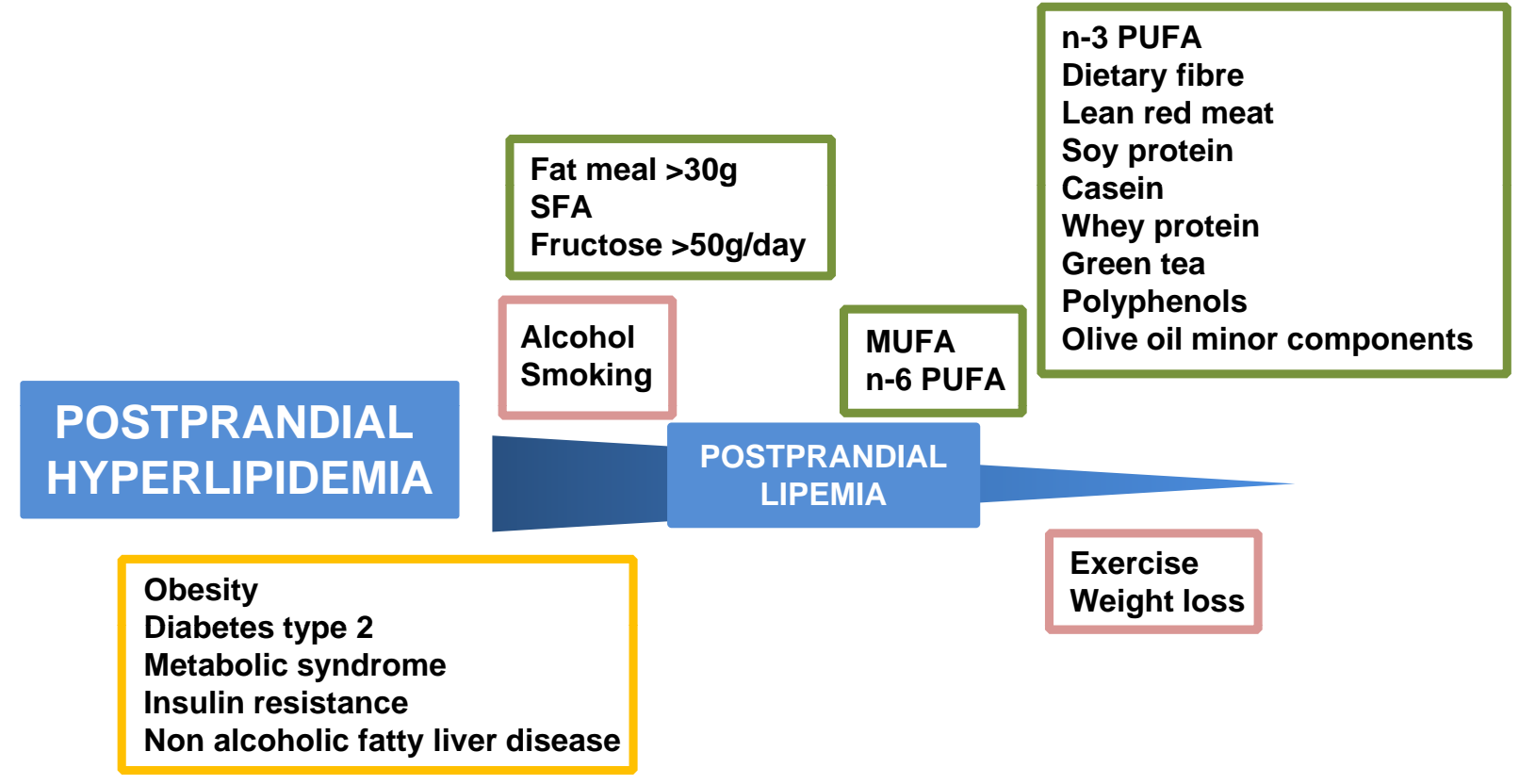

Fig. (1). Lifestyle factors and metabolic diseases affecting postprandial lipemia. 
although they do lead to accumulation of $\mathrm{CM}$ in the late stages of the postprandial phase [66]. In contrast to the effects of digestible carbohydrate, an increase in the content of indigestible carbohydrate (fiber) of test meals by the addition of oat bran, wheat fibre, wheat germ or psyllium husk has been found to reduce postprandial plasma TG concentrations [4, 64, 67].

There is also some limited evidence to suggest that dietary protein quality influences postprandial lipemia. Diets containing lean red meat, soy protein or casein have been shown to reduce postprandial TRL levels [4, 52] and Mortensen et al. [68] have reported that test meals containing whey protein are more effective in improving the lipemic response than those supplemented with casein, gluten or cod protein in patients with type 2 diabetes.

In addition to macronutrients such as fats, carbohydrate and protein, fruit and vegetables contain micronutrients, bioactive compounds such as vitamins, carotenoids, plant sterols and polyphenols, which are believed to contribute to the protective effective against heart disease of diets rich in these foods and of the intake of beverages such as tea and red wine [69]. Consumption of green tea has been found to reduce postprandial lipemia in hypercholesterolemic subjects, and this effect has been attributed to its polyphenol content [70]. Other studies have suggested that the minor constituents of olive oil may reduce the TG content of TRLs postprandially [71], but plant stanols (derivatives of plant sterols) were found to have no effect on postprandial triglyceridemia in patients on lipid lowering therapy [72].

\section{Alcohol, Smoking and Exercise}

Although mild to moderate alcohol intake (equivalent to $0.5-1$ or 1-2 drinks/day for women and men, respectively) is thought to be cardioprotective [73], addition of alcohol to a test meal either as ethanol or red wine has been found to result in a pronounced rise in postprandial lipemia [4, 74], while dealcoholized red wine had no effect [74]. The beneficial effects of moderate alcohol consumption, therefore, are not related to changes in postprandial lipemia. Chronic smoking is also associated with increased postprandial triglyceridemia [4], and this has been attributed to impaired clearance of $\mathrm{CM}$ and CMR [75]. From a study including $>600$ subjects with or without atherosclerosis, Sharrett et al. [6] concluded that, in addition to diet, smoking and alcohol consumption are good predictors of postprandial lipid levels.

The beneficial effects of exercise in reducing postprandial lipemia have been established in a large number of studies [4, 76-79]. Low and moderate volume exercise prior to a fat meal have been shown to decrease the response [76, 78] (although low volume was not effective in smokers [80]), and Singhal et al. [77] reported equally beneficial effects with moderate and high bouts. In addition, a recent review of 16 studies concluded that accumulated exercise (ie in short bouts) may be as effective as continuous exercise in this respect [79]. Moreover, exercise combined with dietary n-3 PUFA supplementation appears to have a synergistic effect in active individuals [4]. The reduction in postprandial lipemia caused by exercise is believed to be due to increased clearance of TRLs which is at least partially mediated by an increase in LPL activity [4].

\section{POSTPRANDIAL LIPEMIA AND METABOLIC DIS- EASES}

Postprandial hyperlipidemia is a feature of common, often inter-related, metabolic diseases, including obesity, insulin resistance, the metabolic syndrome (a combination of obesity, hypertension, insulin resistance/diabetes), non alcoholic fatty liver disease (NAFLD) and type 2 diabetes mellitus [12, 34, 81] (Fig. 1). The rapid increase in the incidence of these diseases in the last three decades, not only in Western Countries but also in the developing world, has reached epidemic proportions. It has been suggested that diabetes is one of the main threats to health in the $21^{\text {st }}$ century, and it has been estimated that there will be 300 million people worldwide with the disease by 2025 [82]. This explosive rise in metabolic disease is linked to the modern, low exercise lifestyle with a diet rich in highly processed, high fat food and relatively low in fruit, vegetables and fibre [82].

Atherosclerosis is the main cause of the increased morbidity and mortality seen in obese patients and is a major cause of death in diabetic patients, and disturbances in postprandial lipid metabolism are particularly implicated in the increased risk [39]. Insulin resistance, a condition commonly found across the different metabolic diseases, is believed to be the primary contributory factor to the postprandial hyperlipidemia [83]. The dyslipidemia is caused by the accumulation of TRLs in the blood due to delayed clearance of CM and CMR coupled with overproduction of these lipoproteins by the intestine and of VLDL by the liver [81, 83, 84].

Factors involved in the excess production of CM in intestinal cells in insulin resistance are thought to include; increased free fatty acid flux into the intestine due to lack of suppression of lipolysis by insulin in adipose tissue; decreased intestinal insulin signaling; and raised activity of the microsomal triglyceride transfer protein (MTP), which is required for $\mathrm{CM}$ assembly [84, 85]. The expression of Niemann Pick C-like 1 protein, which regulates intestinal cholesterol absorption, has also been reported to be increased in a rat model of type 2 diabetes, while at the same time there was a decrease in expression of the ATP-binding cassette transporters (ABC) G5 and G8, which export cholesterol back into the lumen of the intestine [86]. In addition, it has been suggested that alterations in the production or action of glucagon-like peptide-1 and -2, which have been implicated in the regulation of CM formation, may also play a role [84]. The delayed clearance of the intestinally derived lipoproteins is believed to be caused by a reduction in the activity of LPL and hepatic lipase, increased competition for lipolysis by LPL because of the rise in VLDL levels, and decreased uptake by the liver due to lower concentrations of apoE in the particles, increased competition for receptors from VLDL and impairment by hyperglycemia [39, 81, 83, 87].

Insulin resistance is also associated with the overproduction of large VLDL by the liver, and this effect has been shown to be due to disturbances in the assembly of the particles within the hepatocyte [88]. Current evidence indicates that VLDL assembly occurs in the rough endoplasmic reticulum (ER) in two steps. Firstly, apoB and TG are brought together in the membrane of the rough ER by a process enhanced by MTP, and further lipidation leads to the formation of a TG poor VLDL particle which may either be secreted, or further lipidated in the second step to form the larger TG- 
rich VLDLs [88-90]. The TG for the second lipidation step is translocated into the ER lumen by MTP to contribute to VLDL assembly, but may also be returned to the cytosol in a pathway promoted by insulin [89]. In addition, insulin inhibits the expression of MTP, and has also been reported to inhibit the activity of the transcription factor Foxa2, which increases MTP activity [88]. Thus, in normal conditions, insulin down-regulates secretion of the larger VLDL by decreasing the supply of TG for the particles via down regulation MTP activity and diversion of TG to the cytosol, but in insulin resistance these mechanisms fail and there is overproduction of TG-rich particles [88, 89, 91]. In addition to the effects of insulin, it has been suggested that hyperglycemia may play a role in the regulation of hepatic VLDL secretion. High blood glucose levels have been shown to down regulate the secretion of TG in VLDL in normal rats via hypothalamic glucose-sensing mechanisms which act to decrease the activity of stearoyl CoA desaturase-1, an enzyme which promotes VLDL secretion, and to alter a late step in the particle assembly process $[88,92]$. This effect, however, was not observed in animals with diet-induced obesity [92], thus it may be a contributory factor in the enhanced production of VLDL in metabolic diseases.

The overproduction of large TG-rich VLDL in insulin resistance and type 2 diabetes is linked to the other dyslipidemias of the atherogenic lipid triad, high levels of small dense LDL and decreased HDL concentrations [51]. The larger particles facilitate the transfer of TG from VLDL to LDL by cholesteryl ester transfer protein (CETP), forming TG-rich LDL which are then preferentially lipolyzed by hepatic lipase to produce the small dense LDL. A similar process involving CETP and hepatic lipase also leads to the formation of small dense HDL which are catabolized at a faster rate, causing plasma HDL levels to fall [88].

The accumulation of TRLs in the circulation in metabolic diseases such as, obesity, insulin resistance and type 2 diabetes provides an increased opportunity for interaction with the artery wall and the promotion of a series of events which lead to the initiation of atherosclerotic lesions. Remnant lipoproteins have been shown to penetrate the vessel wall as efficiently as LDL and to cause foam cell formation [34]. In addition, however, evidence suggests that they may upregulate the expression of adhesion molecules on endothelial cells and activate leukocytes, thus facilitating their entry into the artery wall, where they differentiate into macrophages eventually become foam cells $[12,40]$. TRLs from hyperlipidemic subjects have been shown to up-regulate the expression of pro-inflammatory genes in human endothelial cells, including those coding for the adhesion molecules, vascular cell adhesion molecule-1 (VCAM-1) and intercellular adhesion molecule-1 (ICAM-1) [37, 38], and Castro Cabezas and colleagues have demonstrated that there is an increase in neutrophil numbers after a fat meal, accompanied by an increase in plasma inflammatory cytokines [12] which could contribute to endothelial dysfunction. Leukocytes have also been found to take up lipid from TRLs, and to be activated during postprandial lipemia and by CMR, and both types of white blood cells appear to take up TRLs and become lipid enriched in this period $[12,40]$.

In addition to the vascular dysfunction caused by the increased residence time of TRLs in the circulation, however, in metabolic disease the situation is exacerbated by adverse effects of insulin resistance on the vasculature. Raised plasma glucose and insulin concentrations together with impaired insulin signaling and increased oxidative stress are believed to cause an imbalance in the release of vasodilators and vasoconstrictors and a loss of endothelial-derived nitric oxide bioavailability, as well as increased blood levels of the pro-inflammatory cytokine tumor necrosis factor $\alpha$ (TNF $\alpha)$, which itself can directly alter signaling via the insulin receptor, and all these effects lead to endothelial dysfunction [82, 93, 94]. Furthermore, increased macrophage apoptosis causing cytokine release in the absence of the normal protective effect of insulin may also be an aggravating factor [95].

As well as the changes in cellular function discussed above, insulin resistance also causes modifications in the arterial intima extracellular matrix that are implicated in the increased risk of atherosclerosis development [96]. The binding of apoB containing lipoproteins, including LDL and TRLs, to glycosaminoglycans (GAGs) in proteoglycans in the extracellular matrix causes retention of the lipoproteins in the vessel wall, and is one of the initiating events in atherogenesis [96, 97]. Insulin resistance and type 2 diabetes have been shown to be associated with an increase in GAG length which leads to increased proteoglycan-lipoprotein binding and thus increased retention of the lipoprotein particles in the intima, and this effect has been attributed to raised circulating levels transforming growth factor- $\beta$ (TGF- $\beta$ ) [96]. Postprandial lipemia may be of particular importance in this mechanism, since a number of studies have suggested that apoB48, found in CM and CMR, has a greater affinity for proteoglycan binding than apoB100, which is found in LDL [96]. Work by Proctor and colleagues has indicated that CMR are co-localized with the proteoglycan, biglycan, in the sub- endothelium of the artery wall in vivo, and although they found no difference in the binding affinity of human biglycan for CM/CMR as compared to LDL in experiments in vitro, the results suggest that the mass of cholesterol bound in CMR is greater than that in LDL [96].

Another possible link between metabolic diseases and postprandial lipemia is adipose tissue. As well as providing a store of energy for the body in the form of TG, adipose tissue actively secretes a number of hormones, including adipokines such as leptin and adiponectin and acylation stimulating protein (ASP) (also called C3adesArg), which is produced on activation of the alternate complement system [98]. Low serum levels of adiponectin have been found to be associated with increased postprandial lipemia and impaired TRL metabolism, and since they correlate with the accumulation of fat in the liver in NAFLD and with the severity of liver histology in non alcoholic steatohepatitis (NASH), this is likely to be due to effects on liver lipid metabolism [99, 100]. Adipocyte production of TNF- $\alpha$ is also raised in insulin resistance, and as well as direct effects on insulin signaling, this leads to down-regulation of genes regulating lipid storage such as LPL and glycerol phosphate dehydrogenase [93]. ASP increases the storage of TG in adipose tissue, and also inhibits TG lipolysis [93, 98]. Plasma levels of fasting ASP have been shown to be positively correlated with postprandial TG concentrations, and are also raised in obesity and insulin resistance, but it is not known whether this indicates ASP resistance or whether it is a compensatory response to postprandial hyperlipidemia $[93,98]$. 


\section{TRANSLATION TO PREVENTION}

Because of the increased risk of cardiovascular disease associated with postprandial hyperlipidemia, particularly in conditions such as obesity and type 2 diabetes, it is recommended that it should be treated [101]. Since the modern Western lifestyle is largely responsible for the problem, it seems reasonable to begin by changing in factors such as diet and exercise. It has been suggested that humans are genetically adapted to a hunter-gatherer lifestyle $[73,83]$ and that diets such as the traditional Mediterranean diet are healthy because they match the ancestral eating patterns much more closely than the modern diet. Significant reductions in postprandial lipemia can be achieved by switching to a diet rich in fresh, unprocessed or minimally processed fruit, nuts and vegetables and containing moderate amounts of MUFA (eg from olive oil) and n-3 PUFAs (eg from oily fish) and some high quality protein (eg lean meat), but low in processed carbohydrate and saturated fats [73]. Regular consumption of nuts ( 5 times per week or more) has been reported to reduce diabetes risk by $20-50 \%$, while restriction of the intake of refined carbohydrates such as white bread has been shown to reduce postprandial hypertriglyceridemia and intraabdominal fat in insulin resistant subjects, and replacing it with MUFA from nuts or olive oil (which may be achieved for example, by replacing sugary snacks with nuts) has been found to have similar beneficial effects [73]. One reason for this is that remnant clearance seems to be optimized when the particles are enriched in TG with MUFA in the glycerol 2-position [102]. Dietary n-3 PUFAs are known to lower postprandial plasma TG levels in healthy individuals, and experiments with animal models of insulin resistance have shown that they reduce postprandial lipemia and the intestinal production of apoB48 containing lipoproteins [103, 104].

In addition to dietary changes, weight loss, increased physical activity and cessation of smoking can also help to correct the postprandial hyperlipidemia associated with metabolic diseases $[4,6,73,75-80]$. Weight loss of $>5 \%$, preferably via a diet that restricts the intake of processed carbohydrates and saturated fats, reduces postprandial lipemia and the associated inflammatory effects [74], and Volek et al. [105] have reported that a carbohydraterestricted as compared to a low fat hypocaloric diet is more effective in subjects with the metabolic syndrome. In addition, exercise improves insulin sensitivity and lowers blood postprandial TG levels, and two recent studies have concluded that exercise of moderate intensity before a fat meal attenuates postprandial hypertriglyceridemia in insulin resistant males [106, 107]. These findings suggest that if the main meal of the day were routinely preceded by a period of exercise, chylomicron clearance should be optimized. Thus, it may be beneficial if the main meal were taken at lunchtime with only a light evening meal, instead of the main meal at the end of the day followed by physical inactivity, which is the current pattern in most Western societies. Intervention studies could easily test these hypotheses.

There are a number of possible pharmacological approaches which may be effective in reducing postprandial hyperlipidemia in obese and diabetic patients, including statins, fibric acid derivatives, nicotinic acid, and oral omega-3 fatty acid supplements [81, 101]. However, the changes in diet indicated above, coupled with weight loss and increased exercise, can be remarkably effective in producing immediate improvements [73] and pharmacological intervention is warranted only in the event that the desired reduction is not achieved after 3 to 6 months of the lifestyle changes [81, 101].

\section{BIOMARKERS}

Alterations in fasting plasma lipid lipoprotein concentrations are known to influence the risk of CVD [108]. In the last decades it has been established that total plasma cholesterol and LDL cholesterol are the best biomarkers of plasma lipemia for evaluation of CVD risk. Using LDL levels, the prevention of CVD is mainly based on a pharmaceutical approach (use of statins), which has proved to be extremely effective [108]. However, LDL elevation is absent in many patients with atherosclerosis and about $1 / 3$ of heart attacks remain unpredicted by this parameter. Furthermore, in fasting normolipidemic subjects [21, 109] increased CVD risk is associated with an exaggerated postprandial lipemic response.

A second factor in CVD prevention is based on changes in lifestyle, and there is a growing consensus that plasma TG levels may be a better reflection of aspects of lipid metabolism that are not revealed by the plasma cholesterol profile. Dietary change, body weight control, increased physical activity, sleeping modality and cessation of smoking are the most common interventations to prevent and reduce cardiovascular risk and related complications associated with metabolic diseases [4,6,73, 75-81]. In the last decades most of these recommendations have developed empirically, mainly on the base of epidemiological studies, without clear understanding of the underlying mechanisms. Although the importance of postprandial metabolism has been debated for a long time, nowadays, as reported above, sufficient evidence exist that atherosclerosis can develop as a consequence of disordered CM metabolism, and that this is probably the most common etiology, as it occurs in patients with CHD and other associated conditions such as hypertension, familiar hypercholesterolemia, obesity, metabolic syndrome, $\mathrm{NASH}$, and renal disease. Acceptance of the role of CM in atherogenesis aids the understanding of the mechanisms underlying empirical risk-reduction strategies, and provides impetus for methodological research to find reliable routine biomarkers of postprandial hyperlipidemia.

Many aspects of studies on CM and CMR metabolism and related topics have been recently reviewed (see Atherosclerosis Supplements Vol. 9, 2008) as well the necessity for a prospective study to investigate the role of postprandial lipid metabolism in CAD [110]. Thus, a major aim of this article is to translate the present knowledge on postprandial lipemia into recommendations for common, more uniform guidelines for a prototype of a routine test for the assessment of this parameter.

Since CM, CMR, VLDL and their remnants all contribute to postprandial TG levels, a deeper understanding of postprandial metabolism in TG-rich lipoproteins necessitates a combination of several methodological approaches [110112]. However, from the clinical point of view, it is relevant that an elevated concentration of TG is the main lipid change found in plasma postprandially, and the magnitude of the response and the slow return to the fasting levels, which 
mainly reflect persistence of CMR in the circulation, is associated with increased risk of CAD [113].

In the future, when accurate and simple methods to separate remnants from other lipoproteins may be available, determination of remnant-cholesterol will be an interesting alternative [24], but, so far, methodological considerations suggest that the most wide-applicable and reliable approaches for the bio-clinical routine laboratory are the determination of plasma TG and apoB48 [114] after consumption of a standard test meal. The advantage of measuring apoB-48 is that this parameter indicates the number of lipoprotein particles of intestinal origin in postprandial plasma, which may be of critical importance in assessing the risk of CVD. It is noteworthy that, in terms of cost/benefit, often a deciding factor for the realization of large non populationaddressed studies, apoB48 determination is far more expensive and less standardized than TG analysis, which thus remains the more appropriate marker to study the postprandial phase in the routine laboratory. In fact, although correlation between fasting and nonfasting TG concentrations is high, evidence suggests that postprandial TG may be a more potent predictor of risk, indicating that the variability in postprandial TG concentration may give relevant information about an individual's metabolism [24,115]. However, although Zilversmit [11] first hypothesized the need to investigate the lipid profile after the administration of an oral test fat meal about 30 years ago, and Karpe proposed a standardized methodology in 1997 [116], the measurement of postprandial TG is still not standard clinical practice, and there remains a lack of consensus on the methodology that should be used to to study postprandial lipemia. There are a number of reasons for this. Firstly, acceptance of the concept of the superiority of the predictive role of non fasting TG over the routine TG fasting determination has been slow. Secondly, questions about the reliability of plasma TG determination, and thirdly a lack of general agreement on guidelines for a standardized postprandial test (meal, sampling time, result calculation, reference values) have also contributed. As the variability of the postprandial response is very high, one obvious obstacle is difficulty in interpretation of the results due to the lack of reference interval values. The last point may be overcome only by wider implementation of postprandial tests and the definition of reference values on the base of geographic background diet differences.

In the past, conflicting conclusions on the role of fasting TG in the evaluation of CAD risk have also been related to analytical considerations. The routine use of fasting TG measurements derived mainly from the necessity of clinicians to use this data to calculate LDL-cholesterol using the Friedewald equation. In comparison to the largely unexplored reference values in the postprandial phase, the consolidated common utilization of this assay has contributed to a better definition of fasting TG plasma reference intervals. However, the variability remains high, mainly because TG is a difficult metabolite to analyze. TG consist of 3 fatty acids esterified to one glycerol molecule. Most of the common methods determine TG in terms of the glycerol content, employing lipase enzymes to remove the fatty acids [117]. TG, however, are a heterogeneous mixture of molecular species with different fatty acid compositions and consequently, different affinities for the lipases used for their assay. This contributes to the large fluctuation in TG determinations over time which have been estimated to have a coefficient of variation $(\mathrm{CV})$ of biological variability averaging about $23 \%$ and ranging up to $40 \%$ [118]. In fact, in individual patient management, single fasting TG measurements are unreliable, with intra-individual CVs up to $60 \%$ [119]. Thus, a long fasting interval (10-12h) before the analysis of post prandial lipemia is generally recommended to lower the withinsubject CV variability. However, as this is influenced by the background diet, the differences cannot be completely abolished. In future, the use of assays that remove or correct for the presence of free glycerol in the sample, for example, by depleting glycerol in a preliminary reaction by the addition of glycerol kinase and catalase, should be encouraged.

Although the first meta-analysis based on Western populations showing that fasting TG is an independent risk factor for CVD, even in the range previously considered to be normal (below $2.0 \mathrm{mmol} / \mathrm{L}$ ) [120], was published in 1996 [121], controversy still exists regarding the clinical usefulness of fasting triglycerides as an independent predictor of risk [122], because adjustment for other covariates, in particular HDL-cholesterol, markedly decreases both the magnitude and significance of observed epidemiologic effects [46, 123]. However, in 2007, two very large independent prospective fully corrected analyses that compared the predictive value of nonfasting TG towards fasting TG reached the conclusion that nonfasting TG is superior to conventional fasting TG in predicting future cardiovascular events after multifactorial adjustment for other cardiovascular risk factors [24,25]. A prospective study of 26,509 women with a follow-up of a median of 11.4 years showed that nonfasting TG is associated with the incidence of cardiovascular events, independent of traditional cardiac risk factors, levels of other lipids, and markers of insulin resistance [ 24,25$]$. In the second prospective cohort study involving the general population of Copenhagen followed for 11 years, elevated nonfasting TG levels were associated with increased risk of myocardial infarction, ischemic heart disease and death [25]. Observations consistent with this have also been made in other studies $[121,124]$, including those on pacific-Asian populations $[116,125]$, and similar conclusions are reported in the first prospective comparison of the association between the metabolism profile of a panel of lipids and CVD depending on the time of last meal [126]. Moreover, van Oostrom et al. [112] have shown that the area under the curve (AUC)-TG, resulting from daylong measurement of capillary blood in free-living subjects, is a better predictor of CVD than fasting lipid parameters such as LDL-cholesterol.

A further potential advantage of moving from fasting to nonfasting TG derives from the observation that postprandial TG levels reflect liver fat content [100, 127]. Matikainen et al. [100] have reported that hepatic fat accumulation is closely correlated to postprandial lipids, and predicts the responses of CM and large VLDL better than measures of glucose metabolism or body adiposity. This growing evidence for the consistency of the predictive role of postprandial TG is increasing the need to perform wider studies involving postprandial metabolism evaluation $[110,111,128]$. It should be noted, however, that separately from the assessment of CVD risk, determination of plasma TG is used routinely for the diagnosis of pancreatitis, and for this purpose, the fasting condition is irrelevant. 


\section{BIOMARKERS FOR POSTPRANDIAL RESPONSE}

The acute metabolic response to a fat meal and nutrients is influenced by several factors. However, on the basis of published reports, there are a number of concepts that may be taken as a base for the standardization of conditions for the determination of nonfasting TG.

\section{Preliminary}

Our aim in this article is to propose a wider use of the routine determination of nonfasting TG as a marker for CVD risk. A complicating factor, however, is that it is practically impossible to avoid the influence of background life style. A general recommendation, therefore, should be to avoid any significant change of the usual diet and habits the day before the test, including alcohol and smoking habits. Extreme physical activity and food excess should also be avoided.

\section{Fat Meal}

A small amount of fat $(<15 \mathrm{~g})$ does not alter plasma lipoprotein levels, but the ingestion of about 30-40g induces the secretion of CM with a composition which is highly dependent on quantity and type of fat, energy intake, carbohydrate, protein, and other dietary components of the meal [129]. The quantity and quality of the test meal can vary the CM response to a fat challenge by more than $50 \%$. Several fat meals, varying in size and composition [reviewed in 111 and 122] have been used to compare postprandial lipemia in subjects at different disease-risk or to study the response to lipids or other specific foodstuffs or to habitual dietary regimen. Thus, it is not surprising that findings differ between groups.

Size of the meal is a crucial point. In recent literature, no general tendency can be observed in the methods used to calculate the meal size. The administration of a meal with the same components and energy content irrespective of body weights and therefore of blood volumes has been used more often than the approach of sizing the test meal according to the unit dose per Kg body weight or per body surface area $[23,130,131]$. As in adults the main variable of body weight is fat mass, in obese subjects calculations based on body weight can cause an overestimation of lipid load. So far, the interesting idea of using total adipose tissue mass [111] to determine the meal size has not been taken up. In view of the lack of a definitive answer, in order to standardize postprandial lipemia evaluation for ease of clinical use, the simpler approach would be to size the fat load according to the body surface area.

Habitual dietary habits are a strong determinant of postprandial metabolic capacity, and the type of predominant fat in the diet varies in different countries and cultures [54, 131, 132]. Thus, it may be not important to specify a particular type of fat for use in clinical practice, but rather to use typical components of the region and, possibly, to align the timing of the test with normal habits. This would be the best solution for routine assessment. However, given the important effect that the degree of fatty acid saturation present in dietary TG have on postprandial lipemia, it is desirable that test meals used for this type of study have a similar degree of saturation level in all parts of the world.
The first type of test meals used were based on dairy-fat based snacks [111, 133, 134]. However, the need for meals that stimulate the physiological functions of digestive organs, as well as the release of insulin necessary for dietary TG processing, suggest that mixed liquid-solid meals, which favor normal gastric emptying and also contain carbohydrate and protein, are a better choice. At low and very high doses of dietary lipids there is no clear dose dependence of postprandial hypertriglyceridemia on the fat load. However, a dose-dependent increase has been reported with moderate intake of between $30-60 \mathrm{~g}$ of fat [129]. Based on this, a mixed meal, having a total energy content of $650-950 \mathrm{Kcal}$, with $50-65 \%$ from fats, a significant proportion $(25-40 \%)$ from carbohydrate and the remainder from protein, is used most commonly. Another reason why the previous meals containing dairy fats are no longer considered optimal is that they contain significant amounts of short and medium-chain fatty acids that enter the blood directly via the portal route, lowering the triglyceridemic response linked to CM secretion $[55,133,134]$. As the test is also appropriate for at risksubjects or patients, the standardized fat meal should have a moderately high energy content of about $600-800 \mathrm{kcal}$.

The carbohydrate content $(50-100 \mathrm{~g})$ of the meal is important to ensure the effective release of insulin. However, the nature as well as the amount of carbohydrate can influence postprandial lipid responses [135]. Meals containing highly digestible starch food seem preferable to those containing glucose and fructose, and those containing slowly digestible carbohydrate that induces low glycemic and insulinemic responses have been reported to decrease postprandial hyperlipidemia in obese subjects [66]. Thus, it is important to determine the effects of the starch source in the meal on plasma glucose and insulin during such studies performed either in normal or at risk-subjects or in patients [111].

Concerning the effect of cholesterol, it has been shown that a chronic diet enriched with dietary cholesterol does not elicit noticeable changes in postprandial lipemia [136]. Prediction of the effect of the meal cholesterol content on postprandial triglyceridemia, however, is complicated because of the prolonged multi-phase duration of its absorption [132]. The data currently available suggests that more than $250 \mathrm{mg}$ of cholesterol in the test meal enhances the postprandial increase in CM-TG [129]. Therefore, a standardized test meal for biochemical evaluation of postprandial lipemia should include a defined low to moderate dose of cholesterol (200250mg).

Taking into account the factors discussed above, we propose a possible breakfast test meal developed on the basis of Mediterranean (Italian) habits and food ingredients.

\section{Breakfast Cake}

Flour: $300 \mathrm{~g}$

Sugar: $200 \mathrm{~g}$

Olive oil: $220 \mathrm{~g}$

Dry almonds: $300 \mathrm{~g}$

Eggs: 5

Baker's yeast: $65 \mathrm{~g}$ 
Consumption of $130 \mathrm{~g}$ of this cake with a little Italian bitter coffee provides an $807 \mathrm{kcal}$ breakfast, of which 475 $\mathrm{kcal}(59 \%)$ is fat. This meal has several advantages. Change of the source of fat (type of oil, margarine butter) can be made depending on dietary habits in different geographical regions, while most of the other ingredients are used worldwide in cakes and pastry.

\section{Schedule Time}

Studies on the effects of the time of day of consumption of a fat meal on the postprandial lipemic response have shown that there is a clear circadian variation [137-139]. Compared with breakfast time, the same meal consumed at lunch elicited a significantly smaller rise in plasma TG. In addition, compared with a morning or mid-day test in the same patients, a nocturnal test showed a later or increased peak TG concentration and a delayed return to baseline concentrations. The nocturnal test was better tolerated in the patients because it did not disrupt their normal activity and eating patterns, as morning tests often do. Some other studies have been conducted overnight following an evening meal $[54,111]$, with standardization of the preceding day's food intake. Overnight studies allow blood sampling to be continued for 12-14 $\mathrm{h}$ and demonstrate that TG return towards 'fasting' levels only in the early hours of the morning (04000500 hours) after a meal the night before (1900 hours) [137, 139]. Thus, standardization of the time of day at which the postprandial TG test is performed is essential.

For routine clinical purposes, the morning is the most suitable time of the day to perform the test. Common sense suggests, therefore, that both to improve patient acceptance and to incorporate the meal into the usual daily habits, it should be similar to typical regional breakfast. A basal blood sample should be withdrawn from the subject after an overnight fast and a short rest in the laboratory, followed shortly afterwards by consumption of the test meal in a fixed time (15-20 min). Delayed clearance of postprandial TG is the main hallmark of a hyperlipidemic postprandial response. Most of the studies now available agree that most informative TG determinations are those at 3-6 h after the meal [24, $25,111,122]$. Measurements made at baseline and after $4 \mathrm{~h}$ (expected peak) and $8 \mathrm{~h}$ postprandially correlate well with data obtained using more frequent time points [140] . Bansal et al [24] showed that in fully adjusted analysis, TG levels measured 2 to $4 \mathrm{~h}$ postprandially had the strongest association with cardiovascular events [25]. Thus, based on current evidence, the best recommendation is to take postprandial blood after $4 \mathrm{~h}$. If this is impracticable, for example for subjects who are in full time employment, a longer, rather than shorter time is advisable.

\section{Calculation}

Calculation of the results is the final step. Although the ultimate aim is to encourage a more widespread use of the determination of postprandial TG levels to assess CVD risk and to reach a consensus on a single determination of postprandial TG, because of the current lack of availability of reliable reference values, it will be necessary, at least in the preliminary phase, to evaluate individual postprandial responses by determining the incremental postprandial TG concentration in relation to the baseline value. In the past, several methods have been used for calculating and expressing the data obtained during postprandial studies. It is now clear that when several determinations are available, the most correct way is to calculate the AUC generally, by the trapezoidal method. For follow-up, in the case of basal and 4 $\mathrm{h}$ determinations, the incremental concentrations obtained by subtracting baseline values from those obtained postprandially (baseline value becomes 0 ) may represent the best way to represent the relative changes from baseline at the different time points. For the early phases of routine determination of nonfasting TG, both the absolute concentration and the $4 \mathrm{~h}$ increment could be useful to the clinician, both to evaluate the postprandial response and the way in which it may be influenced by changes in lifestyle habits or pharmaceutical therapy.

Although reference interval values will need to be evaluated in individual populations under the conditions of the chosen meal, to support the initial studies we report in Table 2 indicative values of postprandial lipemia $4 \mathrm{~h}$ after consumption of a mixed solid meal $[122,140,141]$. As reported in the text a number of lifestyle factors and related diseases (diabetes, obesity, smoke, hypertension, etc) may induce alterations in postprandial triglyceridemia, and intermediate values may be of particular interest to evaluate therapeutical efficacy. This table also reports cholesterol levels, however, postprandial cholesterolemia has little, if any, clinical value, and fasting blood cholesterol levels are a better index for diagnostics, therapeutics and disease prevention.

\section{FUTURE}

In view of recent studies showing that a single nonfasting plasma TG measurement is a better independent predictor of CVD risk than fasting TG [13, 24, 25], several authors hoped for prognostic prospective studies [110, 111, $122,128]$ with standard meals to facilitate a move from fasting to nonfasting TG assay as a routine clinical test. However, the translation to clinical routine of a nonfasting TG test for its prognostic value may still be hampered by cost/benefit considerations. On the other hand, current knowledge of CMR metabolism indicates that the fat load test meal is not only of benefit prognostically, but is also important therapeutically. When pathological changes in postprandial TG reflect CMR clearance times, then positive responses to life style/drug interventations should be accompanied by changes in the nonfasting TG response. As several options for lifestyle improvement as well as a number of different type of drugs [142] are available for medical inter-

Table 2. Plasma Triacylglycerol and Cholesterol Values in Normal and Disturbed Postprandial Lipemia

\begin{tabular}{|c|c|c|c|c|c|}
\hline \multicolumn{3}{|c|}{ Triacylglycerol mmol/L } & \multicolumn{3}{c|}{ Cholesterol mmol/L } \\
\hline Healthy & Intermediate & Alteration & Healthy & Intermediate & Alteration \\
\hline \hline$<2.0$ & $2.1-2.7$ & $>2.8$ & 5.1 & - & $>5.3$ \\
\hline
\end{tabular}


ventation, the option of evaluating changes in CMR metabolism by determination of nonfasting TG is fascinating and likely to increase knowledge on the relationship between empirical life style recommendations and postprandial hyperlipidemia.

The last considerations of this article are about the importance of the topic addressed by this paper in relation to the large social, economic, public health issues, and the translation of our extensive knowledge on the role of nutrition in health into national and international policy [143]. At the population level, a healthy diet and appropriate exercise throughout life can reduce the threat of a global epidemic of chronic diseases [143-145]. Considering the prediction that, if current trends continue, the worldwide incidence of type 2 diabetes will reach 300 million by 2025 [82], there would clearly be a favourable cost/benefit in investing in psychological support to help people to make healthier lifestyle choices. The world-wide aim of National Public Health Systems is to promote the new field of 'public nutrition' as a means to address, in a more efficient, sustainable and ethical manner a population-level approach to the prevention of the major nutrition-related health problems. Greater use of postprandial lipid determination would contribute to the establishment of an evidence-based approach to the implementation and evaluation of empirical interventations which aim to improve the nutrition-related health in the population.

\section{ACKNOWLEDGEMENT}

Part of the work discussed was supported by the Ricerca Finalizzata of the Italian Ministry of Health (Ref ISS R26).

\section{ABBREVIATIONS}

\begin{tabular}{|c|c|c|}
\hline ASP & $=$ & acylation stimulating protein \\
\hline apo & $=$ & apolipoprotein \\
\hline $\mathrm{CM}$ & $=$ & chylomicrons \\
\hline $\mathrm{ABC}$ & $=$ & ATP-binding cassette transporters \\
\hline CETP & $=$ & cholesteryl ester transfer protein \\
\hline CMR & $=$ & chylomicron remnants \\
\hline CVD & $=$ & cardiovascular disease \\
\hline GAGs & $=$ & glycosaminoglycans \\
\hline ICAM-1 & $=$ & intercellular adhesion molecule-1 \\
\hline LPL & $=$ & lipoprotein lipase \\
\hline LDL & $=$ & low density lipoprotein \\
\hline MTP & $=$ & microsomal triglyceride transfer protein \\
\hline MUFA & $=$ & monounsaturated fatty acids \\
\hline NAFLD & $=$ & non-alcoholic fatty liver disease \\
\hline NASH & $=$ & non-alcoholic steatohepatitis \\
\hline PUFA & $=$ & polyunsaturated fatty acids \\
\hline PAI-1 & $=$ & plasminogen activator inhibitor type 1 \\
\hline ER & $=$ & rough endoplasmic reticulum \\
\hline SFA & $=$ & saturated fatty acid \\
\hline TGF- $\beta$ & $=$ & transforming growth factor- $\beta$ \\
\hline TG & $=$ & triacylglycerols \\
\hline
\end{tabular}

TRLs = triglyceride-rich lipoproteins

$\mathrm{TNF} \alpha=$ tumour necrosis factor $\alpha$

VCAM-1 = vascular cell adhesion molecule-1

VSMCs = vascular smooth muscle cells

VLDL = very low density lipoprotein

\section{REFERENCES}

[1] Allender S, Scarborough P, Peto V, et al. European Cardiovascular Disease Statistics 2008 ed. European Heart Network. Available from http://www.ehnheart.org/

[2] Lloyd-Jones D, Adams R, Carnethon M, et al. Heart Disease and Stroke Statistics-2009 Update. A Report From the American Heart Association Statistics Committee and Stroke Statistics Subcommittee. Circulation 2009; 119: e21-e181.

[3] Wing J, Winlansky ME. Lifestyle choices and endothelial function: risk and relevance. Curr Vasc Pharmacol 2009; 7: 209-24.

[4] Lopez-Miranda J, Williams C, Lairon D. Dietary, physiological, genetic and pathological influences on postprandial lipid metabolism. Br J Nutr 2007; 98: 458-73

[5] Perez-Martinez P, Lopez-Miranda JL, Perez-Jiminez F, Ordovas JM. Influence of genetic factors in the modulation of postprandial lipemia. Atheroscler Suppl 2008; 9: 49-55.

[6] Sharrett AR, Heiss G, Chambless LE, et al. Metabolic and lifestyle determinants of postprandial lipemia differ from those of fasting triglycerides. Arterioscler Thromb Vasc Biol 2001; 21: 275-81.

[7] Redgrave TG. Formation and metabolism of chylomicrons. Int Rev Physiol 1983; 28:103-30.

[8] Yu KC, Cooper AD. Postprandial lipoproteins and atherosclerosis. Front Biosci 2001; 6: D332-54.

[9] Nguyen P, Leray V, Diez M, et al. Liver Lipid Metabolism. J Anim Physiol Anim Nutr (Berl) 2008; 92: 272-83.

[10] Gibbons GF. Assembly and secretion of hepatic very-low-density lipoprotein. Biochem J 1990; 268: 1-13.

[11] Zilversmit DB. Atherogenesis: A postprandial phenomenon. Circulation 1979; 60: 473-85.

[12] Alipour A, Elte JWF, van Zaanen HCT, Rietveld AP, Castro Cabezas M. Novel aspects of postprandial lipemia in relation to atherosclerosis. Atheroscler Suppl 2008; 9: 39-44.

[13] O'Keefe JH, Bell DSH. Postprandial hyperglycemia/hyperlipidemia (postprandial dysmetabolism) is a cardiovascular risk factor. Am J cardiol 2007; 100: 899-904.

[14] Hyson D, Rutledge JC, Berglund L. Postprandial lipemia and cardiovascular disease. Curr Atheroscler Rep 2003; 5: 437-44.

[15] Goldberg IR, Kako Y, Lutz EP. Responses to eating: lipoproteins, lipolytic products and atherosclerosis. Curr Opin Lipidol 2000; 11: 235-41.

[16] Takeichi S, Nakajima Y, Yukawa N et al. Association of plasma triglyceride-rich lipoprotein remnants with "Pokkuri disease". Legal Med 2001; 3: 84-94.

[17] Nakajima K, Nakajima Y, Takeichi S, Fujita MQ. Plasma remnantlike lipoprotein particles or LDL-C as major pathologic factors in sudden cardiac death cases. Atherosclerosis 2008; 198: 237-46.

[18] Boquist S, Ruotolo G, Tang R, et al. Alimentary lipemia, postprandial triglyceride-rich lipoproteins, and common carotid intimamedia thickness in healthy, middle-aged men. Circulation 1999; 100: 723-8.

[19] ter Avest E, Holewijn S, Bredie SJ, Stalenhoef AF, de Graaf J. Remnant particles are the major determinant of an increased intima media thickness in patients with familial combined hyperlipidemia (FCH). Atherosclerosis 2007; 191: 220-6.

[20] Misuguchi Y, Ito T, Owada K. Pathologic findings in rabbit models of hereditary hypertriglyceridemia and hereditary postprandial hypertriglyceridemia. Comp Med 2008; 58: 465-80.

[21] Karpe F, Steiner G, Uffelman K, Olivecrona T, Hamsten A. Postprandial lipoproteins and progression of coronary atherosclerosis. Atherosclerosis 1994; 106: 83-97.

[22] Groot PH, van Stiphout WA, Krauss XH, et al. Postprandial lipoprotein metabolism in normolipidemic men with and without coronary artery disease. Arterioscler Thromb 1991; 11: 653-62.

[23] Patsch JR, Miesenbock G, Patsch W. Relation of triglyceride metabolism and coronary disease. Studies in the postprandial state. Arterioscler Thromb 1992; 12: 1336-45. 
[24] Bansal S, Buring JE, Rifai N, et al. Fasting compared with nonfasting triglycerides and risk of cardiovascular events in women. JAMA 2007; 298: 309-16.

[25] Nordestgaard BG, Benn M, Schnohr P, Tybjaerg-Hansen A. Non fasting triglycerides and risk of myocardial infarction, ischemic heart disease, and death in men and women. JAMA 2007; 298 : 299-308.

[26] Wilhelm MG, Cooper AD. Induction of atherosclerosis by human chylomicron remnants: a hypothesis. J Atheroscler Thromb 2003; 10: $132-9$

[27] Kadar A, Glasz T. Development of atherosclerosis and plaque biology. Cardiovasc Surg 2001; 9: 109-21.

[28] Proctor SD, Vine DF, Mamo JCL. Arterial retention of apolipoprotein $\mathrm{B}(48)$ - and $\mathrm{B}(100)$ - containing lipoproteins in atherosclerosis. Curr Opin Lipidol 2002; 13: 461-70.

[29] Proctor SD, Mamo JC. Intimal retention of cholesterol derived from apolipoprotein B100- and apolipoprotein B48-containing lipoproteins in carotid arteries of Watanabe heritable hyperlipidemic rabbits. Arterioscler Thromb Vasc Biol 2003; 23: 1595-600.

[30] Proctor SD, Vine DF, Mamo JCL. Arterial permeablility and efflux of apolipoprotein B-containing lipoproteins assessed by in situ perfusion and three-dimensional quantitative confocal microscopy. Arterioscler Thromb Vasc Biol 2004; 24: 2162-7.

[31] Pal S, Semorine K, Watts GF, Mamo J. Identification of lipoproteins of intestinal origin in human atherosclerotic plaque. Clin Chem Lab Med 2003; 41: 792-5.

[32] Rapp JH, Lespine A, Hamilton RL, et al. Triglyceride-rich lipoproteins isolated by selected-affinity anti-apolipoprotein B immunosorption from human atherosclerotic plaque. Arterioscler Thromb 1994; 14: 1767-74.

[33] Chung BH, Tallis G, Yalamoori V, Anantharamaiah GM, Segrest JP. Liposome-like particles isolated from human atherosclerotic plaques are structurally and compositionally similar to surface remnants of triglyceride rich lipoproteins. Arterioscler Thromb 1994; 14: 622-35.

[34] Botham KM, Bravo E, Elliott J, Wheeler-Jones CPD. Direct interaction of dietary lipids carried in chylomicron remnants with cells of the artery wall: implications for atherosclerosis development. Curr Pharm Design 2005; 11: 3681-95.

[35] Wheeler-Jones CPD. Chylomicron remnants: mediators of endothelial dysfunction? Biochem Soc Trans 2007; 35: 442-5.

[36] Perona JS, Cabello Moruno R, Ruiz-Gutierrez V. Modulation of the effects of chylomicron remnants on endothelial function by minor dietary lipid components. Biochem Soc Trans 2007; 35: 446-50.

[37] Norata GD, Catapano AL. Triglyceride-rich lipoproteins from normotryglyceridemic subjects and hyperlipidemic patients differently affect endothelial cell activation and gene expression patterns. Circ Res 2007; 100: 381-90.

[38] Norata GD, Grigore L, Raselli S, et al. Triglyceride-rich lipoproteins from hypertriglyceridemic subjects induce a pro-inflammatory response in the endothelium: molecular mechanisms and gene expression studies. J Mol Cell Cardiol 2006; 40: 484-94.

[39] Botham KM, Moore EH, De Pascale C, and Bejta F. The induction of macrophage foam cells by chylomicron remnants. Biochem Soc Trans 2007; 35: 454-8.

[40] Bentley C, Hathaway N, DePascale C, et al. Influence of dietary fats on human monocyte activation in vitro. Atheroscler Suppl 2008; 9: 99-100.

[41] Miller GJ, Martin JC, Mitropoulos KA, et al. Plasma factor VII is activated by postprandial triglyceridaemia, irrespective of dietary fat composition. Atherosclerosis 1991; 86: 163-71.

[42] Byrne CD, Wareham NJ, Martensz ND, et al. Increased PAI activity and PAI-1 antigen occurring with an oral fat load: associations with PAI-1 genotype and plasma active TGF- $\beta$ levels. Atherosclerosis 1998; 140: 45-53.

[43] Hyson DA, Paglieroni TG, Wun T, Rutledge JC. Postprandial lipemia is associated with platelet and monocyte activation and increased monocyte cytokine expression in normolipemic men. Clin Appl Thromb Hemost 2002; 8: 147-55.

[44] Fuhrman B, Brook JG, Aviram M. Increased platelet aggregation during alimentary hyperlipemia in normal and hypertriglyceridemic subjects. Ann Nutr Metab 1986; 30: 250-60.

[45] Packard CJ. Small dense low-density lipoprotein and its role as an independent predictor of cardiovascular disease. Curr Opin Lipidol 2006; 17: 412-7.
[46] Stalenhoef AFH, de Graaf J. Association of fasting and non fasting serum triglycerides with cardiovascular disease and the role of remnant-like lipoproteins and small dense LDL. Curr Opin Lipidol 2008; 19: 355-61.

[47] Berneis KK, Krauss RM. Metabolic origins and clinical significance of LDL heterogeneity. J Lipid Res 2002; 43: 1363-79.

[48] Noto D, Rizzo M, Barbagallo CM, et al. Low-density lipoproteins generated during an oral fat load in mild hypertrigyceridemic and healthy subjects are smaller, denser and have an increased lowdensity lipoprotein receptor binding affinity. Metabolism 2006; 55: 1308-16.

[49] Koba S, Tsunoda F, Hirano T, et al. Postprandial changes in LDL phenotypes in patients with myocardial infarction. Eur J Clin Invest 2005; 35: 171-9.

[50] Blackburn P, Cote M, Lamarche B, et al. Impact of postprandial variation in triglyceridemia on low-density lipoprotein particle size. Metabolism 2003; 52: 1379-86.

[51] Rizzo M, Berneis K. Lipid triad or atherogenic lipoprotein phenotype: a role in cardiovascular prevention? J Atheroscler Thromb 2005; 12: 237-9.

[52] Lairon D. Macronutrient uptake and modulation on chylomicron production and clearance. Atheroscler Suppl 2008; 9: 45-8.

[53] Dubois C, Beaumier G, Juhel C, et al. Effects of graded amounts $(0-50 \mathrm{~g})$ of dietary fat on postprandial lipemia and lipoproteins in normolipidemic adults. Am J Clin Nutr 1998; 67: 31-8.

[54] Zampelas A, Peel AS, Gould BJ, Wright J, Williams CM. Polyunsaturated fatty acids of the n-6 and n-3 series: effects on postprandial lipid and apolipoprotein levels in healthy men. Eur J Clin Nutr 1994; 48: 842-8.

[55] Tholstrup T, Miller GJ, Bysted A, Sandstrom B. Effect of individual dietary fatty acids on postprandial activation of blood coagulation factor VII and fibrinolysis in healthy young men. Am J Clin Nutr 2003; 77: 1125-32.

[56] Sanders TA, de Grassi T, Miller GJ, Morrissey JH. Influence of fatty acid chain length and cis/trans isomerisation on postprandial lipemia and factor VII in healthy subjects (postprandial lipids and factor VII). Atherosclerosis 2000; 149: 413-20.

[57] Berry SE, Miller GJ, Sanders TA. The solid fat content of stearic acid-rich fats determines their postprandial effects. Am J Clin Nutr 2007; 85: 1486-94.

[58] Harris WS, Bulchandani D. Why do omega-3 fatty acids lower serum triglycerides? Curr Opin Lipidol 2006; 17: 387-93.

[59] Harris WS, Muzio F. Fish oil reduces postprandial triglyceride concentrations without accelerating lipid-emulsion removal rates. Am J Clin Nutr 1993; 58: 68-74.

[60] Williams CM, Moore F, Morgan L, Wright J. Effects of n-3 fatty acids on postprandial triglyceride and hormone concentrations in normal subjects. Br J Nutr 1992; 68: 655-66.

[61] Westphal S, Orth M, Ambrosch A, Osmundsen K, Luley C. Postprandial chylomicrons and VLDLs in severe hypertriacylglycerolemia are lowered more effectively than are chylomicron remnants after treatment with n-3 fatty acids. Am J Clin Nutr 2000; 71: 914-20.

[62] Kelley DS, Siegel D, Vemuri M, Mackey BE. Docosahexaenoic acid supplementation improves fasting and postprandial lipid profiles in hypertriglyceridemic men. Am J Clin Nutr 2007; 86: 32433.

[63] Rein P, Saely CH, Aczel S, Patsch B, Drexel H. Omega-3 fatty acids significantly reduce postprandial triglyceridemia in male smokers: a pilot study. Nutr Metab Cardiovasc Dis 2009; 19: e3-4.

[64] Lairon D, Play B, Jourdheuil- Rahmani D. Digestible and indigestible carbohydrates: interactions with postprandial lipid metabolism. J Nutr Biochem 2007; 18: 217-27.

[65] Livesey G, Taylor R. Fructose consumption and consequence for glycation, plasma triacylglcyerol, and body weight: meta-analyses and meta-regression models of intervention studies. Am J Clin Nutr 2008; 88: 1419-37.

[66] Harbis A, Perdreau S, Vincent-Baudry S, et al. Glycemic and insulinemic meal responses modulate postprandial hepatic and intestinal lipoprotein accumulation in obese, insulin-resistant subjects. Am J Clin Nutr 2001; 80: 896-902.

[67] Khossousi A, Binns CW, Dhaliwal SS, Pal S. The acute effects of psyllium on postprandial lipaemia and thermogenesis in overweight and obese men. Br J Nutr 2008; 99: 1068-75.

[68] Mortensen LS, Hartvingsen ML, Brader LJ, et al. Differential effects of protein quality on postprandial lipemia in response to a 
fat-rich meal in type 2 diabetes: comparison of whey, casein, gluten and cod protein. Am J Clin Nutr 2009; 90: 41-8.

[69] Mente A, de Koning L, Shannon HS, Anand SS. A systematic review of the evidence supporting a causal link between dietary factors and coronary heart disease. Arch Intern Med 2009; 169: 659-69.

[70] Basu A, Lucas EA. Mechanisms and effects of green tea on cardiovascular health. Nutr Rev 2007; 65: 361-75.

[71] Abia R, Pacheco YM, Perona JS, Montero E, Muriana FJ, RuizGutiérrez V. The metabolic availability of dietary triacylglycerols from two high oleic oils during the postprandial period does not depend on the amount of oleic acid ingested by healthy men. J Nutr 2001; 131: 59-65.

[72] Castro Cabezas M, de Vries JH, van Oostrum AJ, Iestra J, van Staveren WA. Effects of a stanol-enriched diet on plasma cholesterol and triglycerides in patients treated with statins. J Am Diet Assoc 2006; 106: 1564-9.

[73] O'Keefe JH, Gheewala NM, O'Keefe JO. Dietary strategies for improving post-prandial glucose, lipids, inflammation, and cardiovascular health. J Am Coll Cardiol 2008; 51: 249-55.

[74] Naissides M, Mamo JC, James AP, Pal S. The effect of acute red wine polyphenol consumption on postprandial lipaemia in postmenopausal women. Atherosclerosis 2004; 177: 401-8.

[75] Mero N, Syvanne M, Eliasson B, Smith U, Taskinen MR. Postprandial elevation of ApoB-48-containing triglyceride-rich particles and retinyl esters in normolipemic males who smoke. Arterioscler Thromb Vasc Biol 1997; 17: 2096-102.

[76] MacEneaney OJ, Harrison M, O'Gorman DJ, et al. Effect of prior exercise on postprandial lipemia and markers of inflammation and endothelial activation in normal weight and overweight adolescent boys. Eur J Appl Physiol 2009; 106: 721-9.

[77] Singhal A, Trilk JL, Jenkins NT, Bigelman KA, Cureton KJ. Effect of intensity of resistance exercise on postprandial lipemia. J Appl Physiol 2009; 106: 823-9.

[78] Pafili ZK, Bogdanis GC, Tsetsonis NV, Maridaki M. Postprandial lipemia 16 and 40 hours after low-volume eccentric resistance exercise. Med Sci Sports Exerc 2009; 41: 375-82.

[79] Murphy MH, Blair SN, Murtagh EM. Accumulated versus continuous exercise for health benefit: a review of empirical studies. Sports Med 2009; 39: 29-43.

[80] Bloomer RJ, Fisher-Wellman KH. Postprandial oxidative stress in exercise trained and sedentary cigarette smokers. Int J Environ Res Public Health 2009; 6: 579-91.

[81] Pastromas S, Terzi AB, Tousoulis D, Koulouris S. Postprandial lipemia: an under-recognized atherogenic factor in patients with diabetes mellitus. Int J Cardiol 2008; 126: 3-12.

[82] Zimmet P, Alberti KGMM, Shaw J. Global and societal implications of the diabetes epidemic. Nature 2001; 414: 782-7.

[83] Hsieh J, Hayashi AA, Webb J, Adeli K. Postprandial dyslipidemia in insulin resistance: Mechanisms and role of intestinal insulin sensitivity. Atheroscler Suppl 2008; 9: 7-13.

[84] Adeli K, Lewis GF. Intestinal lipoprotein overproduction in insulin-resistant states. Curr Opin Lipidol 2008; 19: 221-8.

[85] Duez H, Pavlic M, Lewis GF. Mechanism of intestinal lipoprotein overproduction in insulin resistant humans. Atheroscler Suppl 2008; 9: 33-8.

[86] Tomkin GH. The intestine as a regulator of cholesterol homeostasis in diabetes. Atheroscler Suppl 2008; 9: 27-32.

[87] Castro Cabezas M, Halkes CJ, Erkelens DW. Obesity and free fatty acids: double trouble. Nutr Metab Cardiovasc Dis 2001; 11: 13442.

[88] Adiels M, Olofsson S-O, Taskinen M-R, Borén J. Overproduction of Very Low-Density Lipoproteins Is the Hallmark of the Dyslipidemia in the Metabolic Syndrome. Arterioscler Thromb Vasc Biol 2008; 28: 1225-36.

[89] Gibbons GF, Wiggins D, Brown AM, Hebbachi AM. Synthesis and function of hepatic very-low-density lipoprotein. Biochem Soc Trans 2004; 32: 59-64.

[90] Hussain MM, Rava P, Pan X, et al. Microsomal triglyceride transfer protein in plasma and cellular lipid metabolism. Curr Opin Lipidol 2008; 19: 277-84.

[91] Adiels M, Westerbacka J, Soro-Paavonen A, et al. Acute suppression of VLDL1 secretion rate by insulin is associated with hepatic fat content and insulin resistance. Diabetologia 2007; 50: 2356-65.
[92] Lam TKT, Gutierrez-Juarez R, Pocai A, et al. Brain glucose metabolism controls the hepatic secretion of triglyceride-rich lipoproteins. Nat Med 2007; 13: 171-80.

[93] Cianflone K, Paglialunga S, Roy C. Intestinally derived lipids: metabolic regulation and consequences - an overview. Atheroscler Suppl 2008; 9: 63-8.

[94] Potenza MA, Addabbo F, Montagnani M. Vascular actions of insulin with implications for endothelial dysfunction. Am J Physiol Endocrinol Metab 2009; 297: E568-77.

[95] Iida KT, Suzuki H, Sone H, et al. Insulin inhibits apoptosis of macrophage cell line, THP-1 cells, via phosphatidylinositol-3kinase-dependent pathway. Arterioscler Thromb Vasc Biol 2002; 22: 380-6.

[96] Vine DF, Glimm DR, Proctor SD. Intestinal lipid transport and chylomicron production: Possible links to exacerbated atherogenesis in a rodent model of the metabolic syndrome. Atheroscler Suppl 2008; 9: 69-76.

[97] Camejo G, Olsson U, Hurt-Camejo E, Baharamian N, Bondjers G. The extracellular matrix on atherogenesis and diabetes-associated vascular disease. Atheroscler Suppl 2002; 3: 3-9.

[98] Cianflone K, Xia Z, Chen LY. Critical review of acylationstimulating protein physiology in humans and rodents. Biochim Biophys Acta 2003; 1609: 127-43.

[99] Musso G, Gambino R, Durazzo M, et al. Adipokines in NASH: postprandial lipid metabolism as a link between adiponectin and liver disease. Hepatology 2005; 42: 1175-83.

[100] Matikainen N, Manttari S, Westerbacka J, et al. Posprandial lipemia associates with liver fat content. J Clin Endocrinol Metab 2007; 92: 3052-9.

[101] Ginsberg HN, Illingworth DR. Postprandial dyslipidemia: an atherogenic disorder common in patients with diabetes mellitus. Am J Cardiol 2001; 88: 9-15.

[102] Mortimer BC, Holthouse DJ, Martins IJ, Stick RV, Redgrave TG. Effects of triacylglycerol-saturated acyl chains on the clearance of chylomicron-like emulsions from the plasma of the rat. Biochim Biophys Acta 1994; 1211: 171-80.

[103] Mangat R, Su J, Scott PG, et al . Chylomicron and apoB48 metabolism in the JCR:LA corpulent rat, a model for the metabolic syndrome. Biochem Soc Trans 2007; 35: 477-81.

[104] Levy E, Spahis S, Ziv E, et al. Overproduction of intestinal lipoprotein containing apolipoprotein B-48 in Psammamys obesus: impact of dietary n-3 fatty acids. Diabetologia 2006; 49: 1937-45.

[105] Volek JS, Phinney SD, Forsythe CE, et al. Carbohydrate restriction has a more favorable impact on the metabolic syndrome than a low fat diet. Lipids 2008; 44: 297-309.

[106] Zhang JQ, Ji LL, Fogt DL, Fretwell VS. Effect of exercise duration on postprandial hypertriglyceridemia in men with metabolic syndrome. J Appl Physiol 2007; 103: 1339-45.

[107] Mestek ML, Plaisance EP, Ratcliffe LA, et al. Aerobic exercise in postprandial lipemia in men with the metabolic syndrome. Med Sci Sports Exerc 2008; 40: 2105-11.

[108] Graham I, Atar D, Borch-Johnsen K. European guidelines on cardiovascular disease prevention in clinical practice: executive summary. Fourth Joint Task Force of the European Society of Cardiology and Other Societies on Cardiovascular Disease Prevention in Clinical Practice (Constituted by representatives of nine societies and by invited experts). Eur Heart J 2007; 28: 2375- 414.

[109] Weintraub MS, Grosskopf I, Rassin T, et al. Clearance of chylomicron remnants in normolipidaemic patients with coronary artery disease: case control study over three years. BMJ 1996; 312: 936-9.

[110] Cohn JS. Are we ready for a prospective study to investigate the role of chylomicrons in cardiovascular disease? Atherosclerosis Suppl 2008; 9; 15-8.

[111] Lairon D, Lopez-Miranda J, Williams C. Methodology for studying postprandial lipid metabolism. Eur J Clin Nutr 2007; 61: 1145-61.

[112] van Oostrom AJ, Alipour A, Sijmonsma TP, et al. Comparison of different methods to investigate postprandial lipaemia. Neth J Med 2009; 67: 13-20.

[113] Karpe F. Postprandial lipid metabolism in relation to coronary heart disease. Proc Nutr Soc 1997; 56: 671-8.

[114] Kinoshita M, Kojima M, Matsushima T, Teramoto T. Determination of apolipoprotein B-48 in serum by a sandwich ELISA. Clin Chim Acta 2005; 351: 115-20.

[115] Iso H, Naito Y, Sato S, et al. Serum triglycerides and risk of coronary heart disease among Japanese men and women. Am J Epidemiol 2001;153: 490-9. 
[116] Karpe F. Effects of diet on postprandial lipaemia: a suggestion for methodological standardization. Nutr Metab Cardiovasc Dis 1997; 7: 44-55.

[117] Russell Warnick G, Nakajima K. Fasting versus Nonfasting Triglycerides: Implications for laboratory measurements. Clin Chem 2008; 54: 14-6.

[118] Smith SJ, Cooper GR, Myers GL, Sampson EJ. Biological variability in concentrations of serum lipids: sources and variation among results from published studies and composite predicted values. Clin Chem 1993; 39: 1012-22.

[119] Delawi D, Meijssen S, Castro Cabezas M. Intra-individual variations of fasting plasma lipids, apolipoproteins and postprandial lipemia in familial combined hyperlipidemia compared to controls. Clin Chim Acta 2003; 328: 139-45.

[120] Austin MA, Hokanson JE, Edwards KL. Hypertriglyceridemia as a cardiovascular risk factor. Am J Cardiol 1998; 81: 7B-12B

[121] Stampfer MJ, Krauss RM, Ma J, et al. A prospective study of triglyceride level, low-density lipoprotein particle diameter, and risk of myocardial infarction. JAMA 1996; 276: 882-8.

[122] Kolovou GD, Anagnostopoulou KK, Daskalopoulou SS, Mikhailidis DP, Cokkinos DV. Clinical relevance of postprandial lipaemia. Curr Med Chem 2005; 12: 1931-45.

[123] Sarwar N, Danesh J, Eiriksdottir G, et al. Triglycerides and the risk of coronary heart disease: 10,158 incident cases among 262,525 participants in 29 Western prospective studies. Circulation 2007; 115: 450-8.

[124] Eberly LE, Stamler J, Neaton JD. Relation of triglyceride levels, fasting and nonfasting, to fatal and nonfatal coronary heart disease. Arch Intern Med 2003; 163: 1077-83.

[125] Patel A, Barzi F, Jamrozik K, et al. Serum triglycerides as a risk factor for cardiovascular diseases in the Asia-Pacific region. Circulation 2004; 110: 2678-86.

[126] Mora S, Rifai N, Buring JE, Ridker PM. Fasting compared with nonfasting lipids and apolipoproteins for predicting incident cardiovascular events. Circulation 2008; 118: 993-1001.

[127] Musso G, Gambino R, De Michieli F, et al. Dietary habits and their relations to insulin resistance and postprandial lipemia in nonalcoholic steatohepatitis. Hepatology 2003; 37: 909-16.

[128] Ridker MP. Fasting versus nonfasting triglycerides and the prediction of cardiovascular risk: do we need to revisit the oral triglyceride tolerance test? Clin Chem 2008; 54: 11-3.

[129] Dubois C, Armand M, Azais-Braesco V, et al. Effects of moderate amounts of emulsified dietary fat on postprandial lipemia and lipoproteins in normolipidemic adults. Am J Clin Nutr 1994; 60: 37482.

[130] Lairon D. Nutritional and metabolic aspects of postprandial lipemia. Reprod Nutr Dev 1996; 36: 345-55.

[131] Weintraub MS, Zechner R, Brown A, Eisenberg S, Breslow JL. Dietary polyunsaturated fats of the W-6 and W-3 series reduce postprandial lipoprotein levels. Chronic and acute effects of fat saturation on postprandial lipoprotein metabolism. J Clin Invest 1988; 82: 1884-93.

[132] Beaumier-Gallon G, Dubois C, Senft M, et al. Dietary cholesterol is secreted in intestinally derived chylomicrons during several subsequent postprandial phases in healthy humans. Am J Clin Nutr 2001; 73: 870-7.

[133] Thomsen C, Rasmussen O, Lousen T, et al. Differential effects of saturated and monounsaturated fatty acids on postprandial lipemia and incretin responses in healthy subjects. Am J Clin Nutr 1999; 69: 1135-43.

[134] Mekki N, Charbonnier M, Borel P, et al. Butter differs from olive oil and sunflower oil in its effects on postprandial lipemia and triacylglycerol-rich lipoproteins after single mixed meals in healthy young men. J Nutr 2002; 132: 3642-9.

[135] Hofmann SM, Tschöp MH. Dietary sugars: a fat difference. J Clin Invest 2009; 119: 1089-92.

[136] Ginsberg HN, KarmallyW, Siddiqui M, et al. A dose-response study of the effects of dietary cholesterol on fasting and postprandial lipid and lipoprotein metabolism in healthy young men. Arterioscler Thromb 1994; 14: 576-86.

[137] Romon M, Le Fur C, Lebel P, et al. Circadian variation of postprandial lipemia. Am J Clin Nutr 1997; 65: 934-40;

[138] Hadjadj S, Paul JL, Meyer L, et al. Delayed changes in postprandial lipid in young normolipidemic men after a nocturnal vitamin A oral fat load test. J Nutr 1999; 129: 1649-55.

[139] Burdge GC, Jones AE, Frye SM, Goodson L,Wootton SA. Effect of meal sequence on postprandial lipid, glucose and insulin responses in young men. Eur J Clin Nutr 2003; 57: 1536-44.

[140] Guerci B, Paul JL, Hadjadj S, et al. Analysis of the postprandial lipid metabolism: use of a 3-point test. Diabetes Metab 2001; 27: 449-57.

[141] Rivellese AA, De Natale C, Di Marino L, et al. Exogenous and endogenous postprandial lipid abnormalities in type 2 diabetic patients with optimal blood glucose control and optimal fasting triglyceride levels. J. Clin Endocr Metab 2004; 89: 2153-9.

[142] Tentolouris N, Eleftheriadou I, Katsilambros N. The effects of medications used for the management of dyslipidemia on postprandial lipemia. Curr Med Chem 2009; 16: 203-17.

[143] Margetts B, Warm D, Yngve A, Sjöström M. Developing an evidence-based approach to Public Health Nutrition: translating evidence into policy. Public Health Nutr 2001; 4: 1393-7.

[144] WHO/FAO: Diet, nutrition and the prevention of chronic diseases. World Health Organ Tech Rep Ser 2003; 916:i-viii, 1-149, backcover

[145] Beaudry M, Delisle H. Public('s) nutrition. Public Health Nutr 2005; 8: 743-8.

(C) Bravo et al.; Licensee Bentham Open.

This is an open access article licensed under the terms of the Creative Commons Attribution Non-Commercial License (http://creativecommons.org/licenses/by-nc/3.0/) which permits unrestricted, non-commercial use, distribution and reproduction in any medium, provided the work is properly cited. 